\title{
The effect of vitamin $D$, magnesium and zinc supplements on interferon signaling pathways and their relationship to control SARS-CoV-2 infection
}

\author{
Mohsen Nabi-Afjadi ${ }^{1}$, Hadis Karami ${ }^{2}$, Kaveh Goudarzi ${ }^{3}$, Iraj Alipourfard ${ }^{4}$ and Elham Bahreini ${ }^{5^{*}}$ (])
}

\begin{abstract}
The concern of today's communities is to find a way to prevent or treat COVID-19 and reduce its symptoms in the patients. However, the genetic mutations and more resistant strains of severe acute respiratory syndrome coronavirus 2 (SARS-CoV-2) emerge; the designed vaccines and adjuvant therapies would potentially control the symptoms and severity of COVID-19. The most important complication of this viral infection is acute respiratory distress syndrome, which occurs due to the infiltration of leukocytes into the alveoli and the raised cytokine storm. Interferons, as a cytokine family in the host, play an important role in the immune-related antiviral defense and have been considered in the treatment protocols of COVID-19. In addition, it has been indicated that some nutrients, including vitamin D, magnesium and zinc are essential in the modulation of the immune system and interferon (IFN) signaling pathway. Several recent studies have investigated the treatment effect of vitamin D on COVID-19 and reported the association between optimal levels of this vitamin and reduced disease risk. In the present study, the synergistic action of vitamin D, magnesium and zinc in IFN signaling is discussed as a treatment option for COVID-19 involvement.
\end{abstract}

Keywords: COVID-19, Interferon, Vitamin D, Magnesium, Zinc

\section{Introduction}

Currently, much of the world's attention is focused on finding a way to prevent or treat COVID-19 disease or reduce its symptoms in patients. Many researchers have offered various solutions and recommendations in this regard, but they need to be proven. Severe acute respiratory syndrome coronavirus 2 (SARS-CoV-2) belongs to the positive-strand RNA viruses family with a crownlike appearance. The viral genome contains S, E, M, and $\mathrm{N}$ genes that encode structural proteins and the ORF region, which expresses non-structural proteins such as

\footnotetext{
*Correspondence: Bahreini.e@iums.ac.ir

${ }^{5}$ Department of Biochemistry, Faculty of Medicine, Iran University of Medical Sciences, P.O. Box: 1449614525, Tehran, Iran

Full list of author information is available at the end of the article
}

papain-like protease, 3-chymotrypsin-like protease and RNA-dependent RNA polymerase [1]. The virus spreads by the scattered droplets through coughing, sneezing, or exhaling from a person's mouth and nose with COVID19. The virus enters the nasal system by inhalation and begins to multiply [2].

Among the structural proteins, glycoprotein S or spike protein, which abundantly covers the surface of SARS$\mathrm{CoV}-2$, binds to the host cell receptor of angiotensin-converting enzyme 2 (ACE2). It is the major contributor to virus entry into the cell and causing infection $[3,4]$. Notably, SARS-CoV-2 does not use other coronavirus receptors such as aminopeptidase $\mathrm{N}$ and dipeptidyl peptidase. By binding $\mathrm{S}$ protein to the receptor, transmembrane protease/serine subfamily member 2 (TMPRSS2), a known human protease located primarily in the airways original author(s) and the source, provide a link to the Creative Commons licence, and indicate if changes were made. The images or other third party material in this article are included in the article's Creative Commons licence, unless indicated otherwise in a credit line to the material. If material is not included in the article's Creative Commons licence and your intended use is not permitted by statutory regulation or exceeds the permitted use, you will need to obtain permission directly from the copyright holder. To view a copy of this licence, visit http://creativecommons.org/licenses/by/4.0/. The Creative Commons Public Domain Dedication waiver (http://creativeco mmons.org/publicdomain/zero/1.0/) applies to the data made available in this article, unless otherwise stated in a credit line to the data. 
and alveolar cell membranes, activates and facilitates virus entry into the cell by cleaving protein $\mathrm{S}$ and ACE2. Furin is another enzyme found in the host cell which has a crucial role in the entrance of the virus (Fig. 1) $[5,6]$. In addition to TMPRSS2 and furin, other S-activating proteases including cathepsin L, trypsin, elastase, thermolysin, factor $\mathrm{Xa}$, and plasmin may also have a role as SARS-CoV-2 entry cofactors. In the lack of prior ACE2 binding, these proteases can excessively proteolyze $\mathrm{S}$ proteins and inactivate virus infection [4, 7]. Thus, SARS causes more severe clinical signs and symptoms in tissues with high ACE2 densities on the cell surface, especially vascular endothelial cells of the lung and extrapulmonary tissues such as the gastrointestinal tract, kidneys, liver, testes, and heart [4].

The natural role of ACE2 is to reduce the concentration of tissue angiotensin II (Ang II) by its conversion to Ang-(1-7), which acts as an anti-inflammatory agent. The major pathologic aspect of COVID-19 is the elevation of Ang II levels directly related to viral load and lung damage. Ang II promotes the expression and activation of inflammatory cytokines such as interleukin (IL)- 6 and thrombin formation and inhibition of fibrinolysis. SARSCoV-2 also has a strong affinity to bind to porphyrins and reduces the level of functional intracellular hemoproteins $[4,8]$. Dysfunction of porphyrins and hemoproteins leads to the release of free iron, especially from dying cells, which results in a severe systemic inflammatory response, tissue damage and a pro-thrombotic state [8]. In this situation, the alveolar epithelial barrier is destructed, the lung defense mechanism is weakened and the permeability of the pulmonary arteries increases. It leads to recruitment and influx of activated neutrophils and macrophages, pulmonary edema, and eventually acute respiratory distress syndrome (ARDS). The alveoli infiltrated with activated neutrophils, cytokines/ chemokines, and protein-rich secretions would not

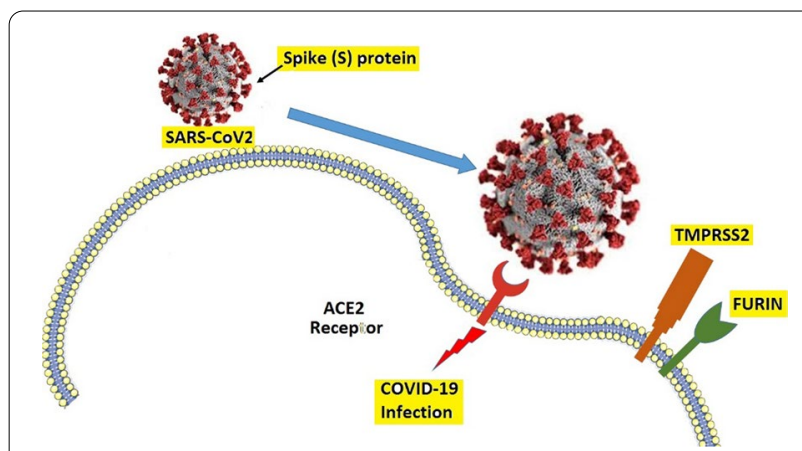

Fig. 1 The role of spike protein and ACE2 receptor in the internalization of SARCE-CoV2. The transmembrane proteases of TMPRSS2 and FURIN 2 facilitate viral infection ventilate enough to provide oxygen. Therefore, some factors by which to strengthen the immune system may help potentialy control COVID-19 and related respiratoty symptoms [8].

At present, there is no assured treatment that can directly target SARSE-CoV2. Moreover, variable genetic mutations and the emergence of more resistant strains of the virus also calls into question the efficacy of designed vaccines. However, several adjuvant therapies can be used to control the symptoms and severity of COVID19 until discovering an anti- SARSE-CoV2 drug in the future. Some vitamins, minerals and herbal derivatives are efficient supplementals in maintaining the function of the immune system and have synergistic effects next to medical therapies $[9,10]$. Previous studies have shown an association between some vitamin and mineral deficiencies and immunodeficiency against respiratory pathogens, as well as more extended recovery periods from disease. For example, it is evidenced that C, D and $\mathrm{E}$ vitamins and some minerals like zinc, selenium, and omega-3 fatty acids enrich the immune system to prevent and treat infectious diseases. It has been claimed that concomitant use of these compounds with azithromycin may be more effective in the rapid recovery of a patient infected by SARS-CoV-2 [11]. Interferons (IFNs) are internal antiviral agents of which, in combination with such supplements, may have synergistic treatment effects on the COVID-19 disease $[12,13]$. Hereby, this article aims to discuss the anti-inflammatory effects of IFNs on SARS-CoV-2 infection and rather complementary effects of vitamin $\mathrm{D}$ and minerals.

\section{The common pattern of virus-induced hyperinflammation of respiratory viruses}

The twenty-first century has a global impact on health due to the spread of a variety of respiratory viruses following successive mutations, which cause acute inflammation with high mortality rates. Overproduction of inflammatory cytokines in various SARS-CoV-2 viral infections indicates a severe immunopathological process $[14,15]$. Due to the manifestations of influenza infection, including high levels of cytokines and chemokines such as IL-6, IL- $1 \beta$, TNF- $\alpha$, IL-10, and elevated serum ferritin levels, a similar association was shown between infection caused by the SARS-CoV-2 viral epidemic and seasonal human influenza viruses [16]. In influenza and COVID-19 infections, cytokine storm is closely related to coagulopathy and disseminated intravascular coagulation [17]. Both influenza and SARS-CoV viruses induce NLRP3 (NLR family pyrin domain containing 3 ) inflammasome activation [18], associated with pyroptosis - a highly inflammatory form of lytic programmed cell death- upon infection with intracellular pathogens. Lymphocytopenia, as well 
as reduced polyfunctionality and cytotoxicity of T-cells and NK cells due to the continuous expression of inhibitory markers such as programmed cell death protein-1 (PD-1) and T-cell immunoglobulin domain and mucin domain protein-3 (TIM-3), are characteristics of both influenza infection and COVID-19 [19, 20]. The reverse correlation between PD-1 and TIM-3 protein markers with total counts of CD8- and CD4-T cells, but not neutrophil counts, makes both parameters a good predictive criterion for COVID-19 progression and severity [20]. TIM-3 participates in cytokine storm during COVID-19 by activating infected macrophages and negatively regulating the Th1 immune response in the cytokine storm, and subsequently causes overstimulation of the innate immune system [20]. In addition to TIM-3, the activation of the PD-1/PD-L1 pathway in severe H1N1 influenza A infection has been demonstrated in tissue samples of the lower respiratory tract in pediatric patients and their dendritic and T cells as well [21, 22]. PD-L1 expression levels are inversely related to the number of CD8 + T cells in these patients, and inhibition of this pathway improves the number and function of CD8 $+\mathrm{T}$ cells [23]. Rutigliano et al. showed that decreased CD8 $+\mathrm{T}$ cells activity in influenza A virus infection in mice was associated with increased PD-1 expression [24]. They found that blocking PD-L1 in vivo can reduce the virus titer and increases the number of $\mathrm{CD} 8+\mathrm{T}$ cells but not their activity. Another study reported that the recovery period from influenza infection in PD-1 -/- mice are much longer than the wild ones [25]. These findings show the dual role of the PD-1/ PD-L1 pathway, which negatively regulates CD8 $+\mathrm{T}$ cells and slows virus clearance.

As mentioned, severe cases of influenza and COVID19 share a similar immune response, including a reduced number of circulating CD8+and CD4+ T cells and increased amounts of proinflammatory cytokines [26, 27]. The lower number of acute immune cells in the acute phase of severe disease may be due to the migration of these cells to the respiratory tract; in fact, there may be no reduction in the production of immune cells. Autopsy of patients with COVID-19 showed diffuse infiltration of lymphocytes, especially $\mathrm{CD} 8+\mathrm{T}$ cells into the lungs, along with focal infiltration into the liver, kidney, pancreas, intestine, adrenal, and pericardium. Such lymphocyte migrations and following cytokine storm could promote apoptosis or necrosis of $\mathrm{T}$ cells and consequently reduce their number in blood circulation [28].

\section{Interventions of IFNs and their agonists with SARS-CoV-2 infection}

The cytokine storm, an abrupt rise of serum inflammatory cytokines and chemokines in SARS-CoV-2, influenza, and MERS-CoV infections trigger a severe systemic inflammatory response that must be controlled to limit tissue damage [16]. Interferon cytokines as the first line of defense against viral infections are secreted by immune-activated cells and activate natural killer cells (NK) and macrophages. Type I IFNs includes IFN- $\alpha$ and IFN- $\beta$, while IFN- $\gamma$ and IFN- $\lambda$ belong to type II and type III IFNs, respectively [29]. IFNs bind to their receptors on the cell surface and activate several genes involved in the antiviral process by inducing the Janus-activated kinase (JAK)/signal transducer and activator of transcription (STAT) signaling pathway. In this signaling pathway, the activated IFN-receptor induces Janus kinase 1 (JAK1) and Tyrosine kinase 2 (TYK2), which then phosphorylate STAT1and STAT2. These phosphorylated factors enter the nucleus and are assembled with interferon-regulatory factor 9 (IRF9). The activated IRF9 stimulates interferonstimulated gene factor 3 (ISGF3) and subsequently the transcription of interferon-stimulated genes (ISGs). ISGs are important contributors to virus-induced immune responses [30,31].

Anti-inflammatory effects are another role of IFNs that are associated with the suppression of pro-inflammatory cytokines such as IL-1, IL-18 and IL-12 and the induction of anti-inflammatory cytokine IL 10. In SARS-CoV-2 infection, there are abnormally low levels of antiviral cytokines, especially type I IFNs $[17,18]$. Therefore, IFNs are considered an important target to control cytokine storms and inflammation within the treatment of COVID-19. A well-documented strategy of coronavirus reported as an elimination of host interferon's defense system through interference to their production and signaling pathway. For example, a reduction in IFN- $\gamma$ expression has been observed in $\mathrm{CD}_{4+} \mathrm{T}$ cells of patients with COVID-19 associated with disease severity [19]. IL-6 can also differentiate Th2 cells from Th0 by activating the STAT3 signaling pathway and eventually producing Th2 cytokines such as IL-13 and IL-4, as well as suppress cytokine signaling 1 (SOCS-1). SOCS-1, as an inhibitory molecule through its effects on STAT1 phosphorylation, can disrupt the production of IFN- $\gamma$ and IL-2 and lead to a decrease in the level of these cytokines by Th1 cells [32]. On the other hand, increasing IL- 6 and finally SOCS- 1 by interfering with STAT4 phosphorylation has an inhibitory effect on IFN- $\gamma$ and IFN-II production. These IFNs are involved in the cytolysis of infected cells by stimulating and activating killer cells, including NK and CD8 + - T cells. One of the main mechanisms in the removal of virus-infected cells in the progression of apoptotic pathways and their associated molecules by pro-apoptotic molecules such as granzyme $B$, which are produced and secreted by killer cells [33]. According to the described mechanism, the survival of infected cells can be affected by IL- 6 because this multifunctional cytokine can induce 
anti-apoptotic molecules by stimulating Th17 differentiation and IL-17 production [33]. Another chosen mechanism by the virus for the development is the cooperation of IL-6 and IFN-I. These cytokines increase the survival of the infected cell by increasing inhibitory molecules such as PD-L1 (CD274) on the surface of the infected cell. The binding of PDL-1 to PD-1 (CD279) on CD8 +-T cells prevents apoptosis induced by these cells [33, 34].

Coronaviruses also avoid interactions with patternrecognition proteins (PRPs) responsible for inducing proinflammatory reactions and antiviral responses mediated by IFN [20]. These mechanisms ultimately interfere with the production of IFNs and cause a delayed antiviral response mediated by IFNs. Some in vitro studies have shown that IFN- therapies can inhibit viral replication and the combination of IFNs has a synergistic effect in this regard [35]. Thus, IFN- therapy is an accepted treatment strategy to induce antiviral immune responses. However, IFN administration in the early stages of infection seems to affect effectively, leading to devastating responses in severe or later stages of the disease [36]. Although antibiotics are known as antibacterial agents, some also have antiviral effects, such as Macrolides. Macrolides composed of a large lactone ring bind to the $50 \mathrm{~S}$ subunit of the bacterial ribosome and interfere with protein synthesis [37]. There are some indications of macrolides to relieve viral respiratory infections [21]. The antiviral activity is attributed to their binding to IFN-receptor and inducing STAT1/2, IRF7, IRF9, and production of ISGF3 as well [22]. Clarithromycin and Leucomycin are the examples of Macrolides, used against the influenza virus to increase IFN- $\alpha$ production $[23,38]$. Azithromycin is another macrolide that inhibits rhinoviruses via potentiating IFN-I signaling. It activates IкB-kinase (IKK), IKK- $1 / \varepsilon$, and TANK-binding kinase 1 (TBK-1) signaling pathway, which stimulates the IRF factor, and IL-28 and IL-29 receptors [39, 40]. Azithromycin can induce the gene expression of IFN- $\beta$ and IFN $\lambda 1$, tolllike receptor 3 (TLR3), melanoma differentiation-associated protein 5 (MDA5), RIG-I-like helicase, and retinoic inducible gene I (RIG-I) in bronchial epithelial cells [40, 41]. The aforementioned agents act as antiviral proteins in rder to reduce the viral load. Azithromycin also improves the cell sensitivity to viral infections through upregulation of pathogen recognition receptors (PRRs) of IFIH1, DDX58, and ISGs including IFITM3, MX1, and RASD2 [42, 43]. In addition to ACE2, CD147 is another binding receptor, that internalizes SARS-CoV-2 virus. Azithromycin may interfere with CD147 and the virus interaction process.

Ribavirin (Virazole), a guanosine analog, is another drug introduced by Witkowski et al. and originally used only to treat severe respiratory syncytial virus (RSV) infection in children [44]. It has a wide range of functions against RNA and DNA viruses, including infection with Lhasa fever virus, influenza $A$ and $B$, and other viruses. It is also effective in combination with IFN- $\alpha$ in the treatment of chronic hepatitis $C$ infections [45, 46]. It combines with viral RNA and, in addition to inhibiting the normal viral replication, causes mutations in its genome. It also inhibits RNA-dependent RNA polymerase activity. Following their bioinformatics studies, it has been claimed that the drug could bind to the active site of the enzyme and, by inhibiting it, could be a potent inhibitor for SARS-CoV-2 infection $[47,48]$.

Studies have indicated that some nutrients, including vitamin $\mathrm{D}$, magnesium and zinc, play an essential role in the immune system and modulate the IFN signaling pathway. Adequate amounts of such micronutrients are crucial to ensure the proper functioning of the immune system. Vitamin D can control the production of proinflammatory cytokines and the cytokine storm observed in COVID-19 through affecting the nuclear factor-kB and other related pathways. Magnesium is a critical cofactor in the synthesis and activation of vitamin D [49]. Zinc is also important for the development of immune and other cells, so its deficiency leads to defects in humoral and cellular immunity [50].

\section{Potential role of activation of the vitamin D in acute respiratory distress syndrome (ARDS)}

Vitamin D (VitD), as one of the oldest evolutionary hormones with a known role in the absorption of calcium from the intestine, plays a role in regulating the immune system [51]. VitD receptor (VDR) is detected in all immune cells especially monocytes and macrophages and regulates their activity. it can potentially prevent a cytokine storm by reducing the expression of pro-inflammatory cytokines. Studies have shown a correlation between VitD deficiency and an increased risk of upper respiratory tract infection. A meta-analysis in 2019, using approximately 10,000 individual participant data from 25 RCTs, concluded that vitamin D supplementation could reduce the risk of upper respiratory infections by $19 \%$. The idea comes to the question is whether this conclusion also applies to coronavirus infections [52].

As shown in Fig. 2, the signaling pathway activated through VitD complexed with its receptor (VDR) reduces cytokine and chemokine storm, modulates neutrophil activity, regulates the renin-angiotensin system (RAS), maintains pulmonary epithelial barrier integrity, and stimulates epithelial repair [53]. Animal studies and in vitro models have detected high levels of VDR in the alveolar type II cells (ACII) of the lung. They have shown that VitD acts like an endocrine system by increasing the production and secretion of cytokines such as 


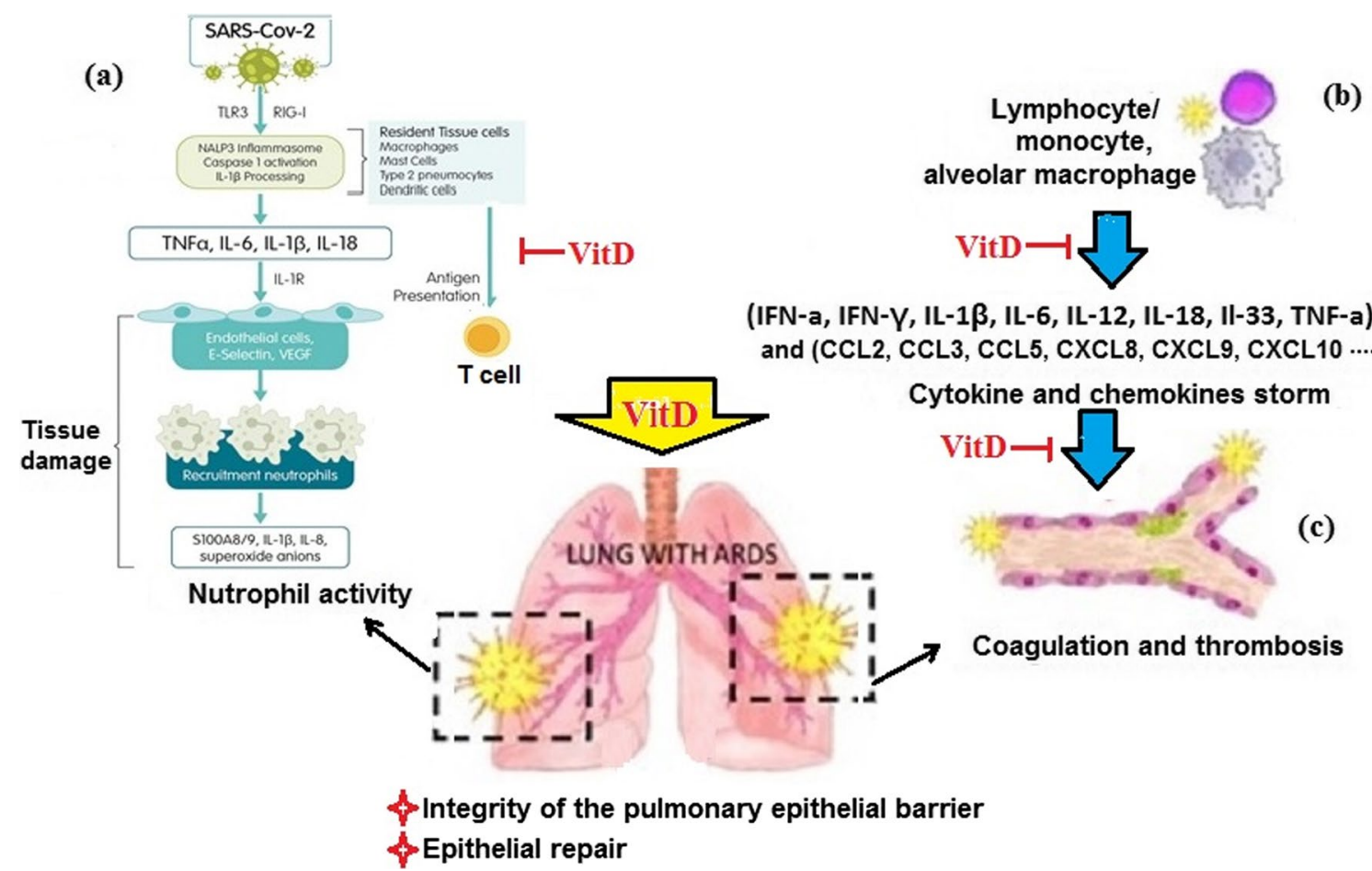

Fig. 2 a recruitment of activated neutrophils into the inflamed interstitium and alveolar space by cytokines and chemokines secreted from infected epithelial and endothelial cells and activated alveolar macrophages; $\mathbf{b}$ cytokines and chemokines secreted by activated leukocytes cause cytokine and chemokine storms that are involved in the pathogenesis of ARDS; $\mathbf{C}$ dysregulation in homeostasis resulted in intra-alveolar or systemic fibrin clots and thrombotic complications. In each mentioned complication, the positive effects of VitD on the prevention and improvement of viral infections have been demonstrated

IL-1 $\beta$, IL-6, IL-12, IL-18, IL-33, IFN- $\alpha$, IFN- $\gamma$, TNF- $\alpha$, and chemokines such as CCL2, CCL3, CCL5, CXCL8, CXCL9, CXCL10 in acute respiratory syndrome [54, 55]. For example, following LPS treatment, VDR-knockout mice had more severe ARDS than wild-type mice. $\mathrm{Xu}$ et al., in their study on the mechanism of VitD effect on acute lung injury (ALI) induced by lipopolysaccharide (LPS) reported that VitD may attenuate LPS-induced ALI by modulating the expression of the RAS components, including ACE, ACE2, renin and Ang II. Li et al., suggested that VitD is a negative endocrine regulator of the RAS and inhibits renin biosynthesis [56]. Ishii showed that inhibition of renin receptors reduces inflammatory symptoms, including interstitial edema, neutrophil count, hemorrhage, and the amount of pro-renin in the lung tissues of the study model [57]. Takano et al. suggested that the inhibitory effects of VitD on neutrophil recruitment in the hamster model of ALI could be due to its suppressive effect on the interleukin-8 (IL-8) gene involved in the pathogenesis of ALI [58].

Some genes regulated by VitD are key genes in the immune system's response to many bacterial and viral infections [59]. Cathelicidin antimicrobial peptides
(CAMP) of LL-37 and FALL-39 are antimicrobial molecules that are primarily synthesized and stored in the lysosomes of polymorphonuclear cells, and macrophages after activation by viruses, bacteria, parasites, fungi. VitD also stimulates the transcription of cathelicidins $[60,61]$. The activated VDR by VitD acts as a transcription factor that influences the transcription of several genes including the hCAP18 gene that encodes cathelicidin. Following cleavage by proteinase 3 , the peptide precursor CAP-18 $(18 \mathrm{kDa})$ is processed into active forms LL-37 and FALL$39[62,63]$.

The mechanism of action of cathelicidins is that, following the phagocytosis of the invasive agent and the attachment of the phagosomes to the lysosomes, the cathelicidins lyse it by damaging and perforating the membrane of the invasive agent cell, and providing the conditions for its complete destruction through lysosomal degrading enzymes. Cathelicidins are also able to destroy the cover of enveloped viruses such as those of the Coronavirus family [64]. Thus, vitamin D can help regulate the immune system response and clear the SARS-CoV-2 virus by producing LL37. Remarkably, exposure to fine particulate air pollution, dust, and 
cigarette smoke can worsen the severity of COVID-19 via reducing effective immune response, modulated by LL37, and interfering with LL37 in the destruction of viruses [65]. Therefore, the use of vitamin D supplements in areas or large cities with air pollution problems can be helpful in the treatment of COVID-19 disease.

Figure 3 shows the possible inhibitory mechanism by VitD to prevent cytokine and chemokine storms by regulating the function of both dendritic cells (DCs) and $T$ cells. In DCs, VitD/VDR complex in the nucleus down-regulates the expression of CD40, CD80, CD86, MHC-II, and up-regulates the expression of IL-3, IL-10 and CCL22, which results in the induction of $\mathrm{T}$ cells [66, 67]. VitD/VDR complex also can control TLRs signaling through inhibition of miR-155-SOCS1 pathway and decrease in the pro-inflammatory cytokine production such as TNF-a, IL-6, and IFN- $\gamma$ [68]. In T-cells, VitD/ VDR can make a complex with RXR that leads to induction of MKP1 and inhibition of the p38-MAP kinase pathway [69]. By inhibiting the MAP kinase pathway, p38 is dephosphorylated, which down-regulates the proinflammatory cytokines such as IFN- $\gamma$, IL-6, Il-17, IL-23 and TNF- $\alpha$. Dephosphorylated p38 can also inhibit the maturation of DCs, and the differentiation of Th1 and Th17 [69, 70].

Nowadays, VitD deficiency is considered a global health problem. Studies have shown a significant association between VitD deficiency and the progression of asthma attacks, which may threaten the persistence of infection and sepsis [71]. A systematic review and meta-analysis examined the efficacy of high-dose VitD in pediatric asthma and showed that high-dose VitD may prevent asthma exacerbations [72]. Also, Jae Hyoung Im and et al. showed vitamin D deficiency with a deficiency $(<20 \mathrm{ng} / \mathrm{dl})$ in $76 \%$ of the SARS-COV-2 infected patients and a severe deficiency $(<10 \mathrm{ng} / \mathrm{dl})$ in $24 \%$ [73]. Thus, these studies again confirm the potential positive effects of VitD supplementation in preventing the severity of COVID-19.

\section{Magnesium effect on COVID-19 through VitD}

Some Studies have established a relation between magnesium deficiency, decreased immune cell activity, and increased inflammation, which could be significant in COVID-19-associated cytokine storm pathology [74]. Magnesium, like other trace elements, acts mainly through its cofactor or structural role for enzymes.

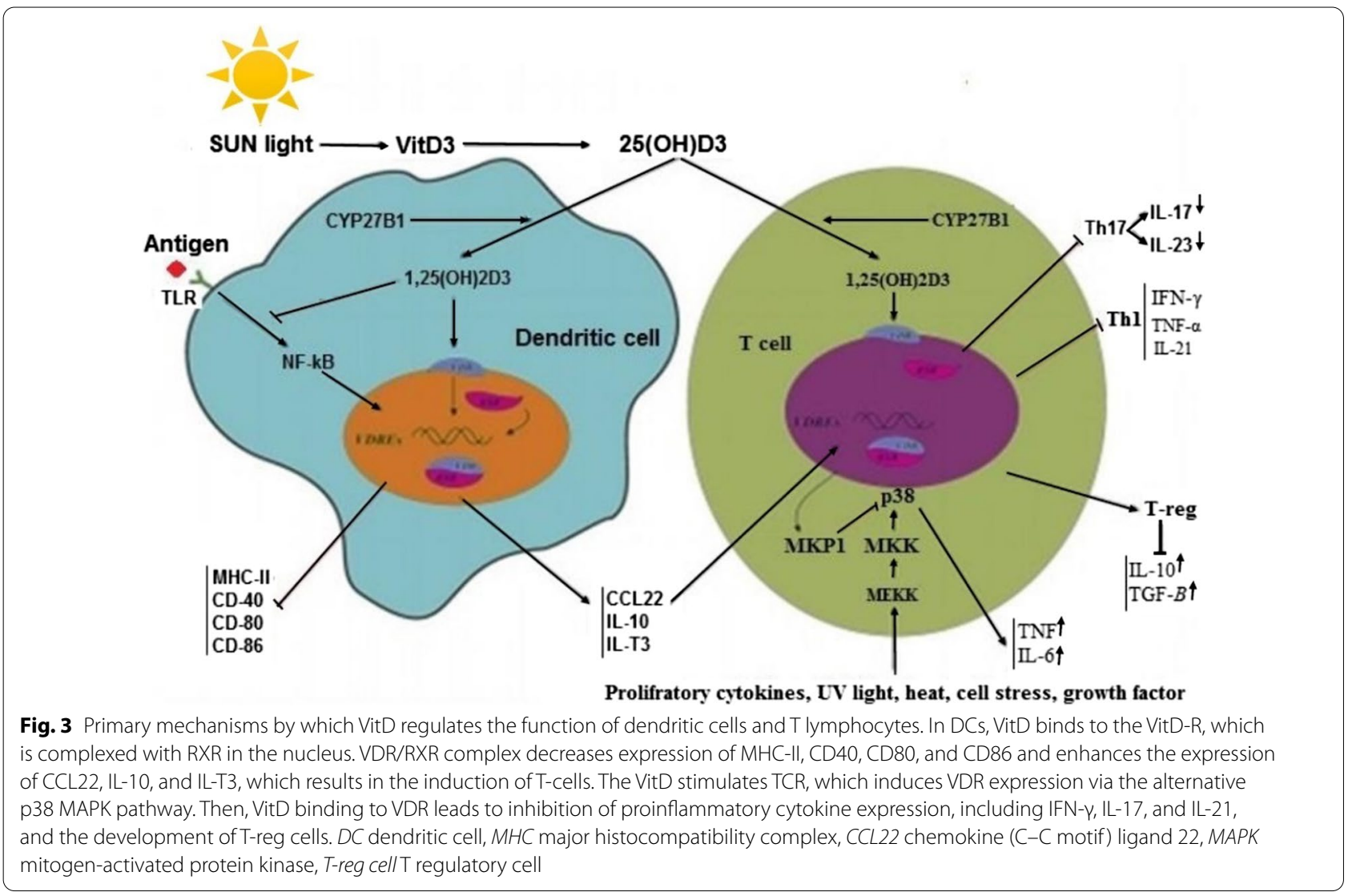


Enzymes containing cytochrome $\mathrm{P} 450$ are examples of these enzymes, which play a role in the metabolism of VitD. They are involved in both the activation and inactivation of VitD [49, 75]. The activation is mediated by 25 -hydroxylase (CYP2R1) and $1 \alpha$-hydroxylase (i.e., CYP27B1), and deactivation is catalyzed by 24-hydroxylase (CYP24A1)[76]. 25-hydroxylation and synthesize of $25(\mathrm{OH}) \mathrm{D}$ from $\mathrm{VitD}_{3}$ or $\mathrm{VitD}_{2}$ is occurred in the liver and followed by $1 \alpha$-hydroxylation of $25(\mathrm{OH})$ $\mathrm{D}$ to active $1,25(\mathrm{OH})_{2} \mathrm{D}$ in the kidney. Both $25(\mathrm{OH}) \mathrm{D}$ and $1,25(\mathrm{OH})_{2} \mathrm{D}$ are metabolized to inactive forms of 24,25-dihydroxyvitamin D and 1,24,25-trihydroxyvitamin D by 24-Hydroxylase, respectively [77]. The dependence of these enzymes on magnesium may indicate the role of magnesium in maintaining active levels of VitD, and in controlling the severity of COVID-19 disease, while it requires more clinical and experimental investigations.

\section{The roles of Zinc in the inhibition of acute respiratory distress syndrome (ARDS)}

Zinc, an important micronutrient especially for enzyme activity and zinc fingers, is essential for regulating both innate and adaptive immune systems and maintaining immune tolerance. It holds the proliferation and maturation of leukocytes and lymphocytes and modulates the inflammatory responses. Several studies have shown the association between zinc deficiency and the prevalence of respiratory infections among the population. Rerk suppaphol et al., in a double-blind placebo study of zinc supplementation in the treatment of acute respiratory tract infections, showed a $45 \%$ reduction in the rate of acute respiratory infections [78]. Singh et al., in their randomized, double-blind, placebo-controlled trial study, reported the ameliorative effect of zinc in reducing the duration of colds [79]. Some other studies have indicated the antiviral activity of zinc against various viruses including influenza [80], rhinovirus, herpes virus, respiratory syncytial virus and transmissible gastroenteritis virus [81]. Such immunomodulatory and antiviral properties of zinc, highlights its potential role as a supportive agent in the treatment of COVID-19.

Zinc deficiency has a significant effect on bone marrow and reduces the production of B lymphocytes and T lymphocytes following a decrease in the number of immune progenitor cells [82]. Its deficiency also alters the function and number of blood polymorphonuclear, NK cells, and lymphocytes, especially T cells [81]. Zinc is a major component of the hormone thymolin, which is involved in the development of $\mathrm{T}$ cells in the thymus gland [83]. It is an essential factor involved in complement activation and helps regulate cytokine secretion such as IL-2, IL-6 and TNF by reducing the formation of pro-inflammatory Th9 and Th17 cells [84]. Zinc induces differentiation of monocytes to macrophages, increases the phagocytic potency of macrophages, and stimulates them to produce IL-12 to activate NK and T cells. Zinc also upregulates the production of IL-2, IFN- $\alpha$ and IFN- $\gamma$ and downregulates the production of IL-10 resulting in to promotion of antiviral reactions. On the other hand, IFNs can stimulate the influx of zinc into the target cells. Decreased levels of IL-10 positively affect macrophage function and Th1 response [81, 85, 86]. IFN $\alpha$ antiviral activity is mediated through JAK1/STAT1 downstream signaling and upregulation of antiviral enzymes, including protein kinase RNA-activated (PKR) and latent ribonuclease (RNaseL) [87]. Such antiviral enzymes are involved in the degradation of viral RNA and inhibition of viral RNA translation. Both IFN- $\gamma$ and IL-12 also play a crucial role in the destruction of various pathogens through a mechanism including downregulation of ERK $1 / 2$ and NF- $\mathrm{kB}$ pathways [88]. Regulation of ERK1/2 and NF- $\mathrm{kB}$ pathways has been shown to be necessary for the protective effect of zinc on the lungs in the infection states. Low zinc status upregulates IKK activity and subsequent NF- $\mathrm{KB}$ signaling resulting in upregulation of target genes of TNF $\alpha$, IL-1 $\beta$, and ICAM-1 $[89,90]$. In their study of primary human lung cells, Bao et al. reported that in the absence of zinc, treatment with IFN- $\gamma$ and TNF- $\alpha$, as well as activation of Fas- $\mathrm{R}$ signaling, would lead to cell apoptosis and impaired pulmonary epithelial barrier function [91]. Aydemir et al. also showed that zinc regulates IFN- $\gamma$ expression in human activated $\mathrm{T}$ lymphocytes isolated from individuals supplemented with $15 \mathrm{mg} /$ day zinc [92]. The upregulated IFN- $\gamma$ in activated human T lymphocytes, reduces the release of the cytokine. Such overall results indicate that zinc is a vital factor in the protection of pulmonary epithelium against acute damage.

\section{Conclusions}

COVID-19, as a potentially life-threatening disease, has received serious attention from researchers using various treatment strategies. Targeted treatments against cytokines can prevent the cytokine storm, which brings the disease to its final stage. VitD, by affecting NF- $\mathrm{kB}$ and other pathways, can attenuate various pro-inflammatory cytokines involved in the cytokine storms. Magnesium, the critical element in the synthesis and activation of VitD, acts as a cofactor for many enzymes involved in VitD metabolism. Low zinc status impairs immune response and increases susceptibility to viral, bacterial, and fungal infections. Excessive inflammatory response overproduces pro-inflammatory cytokines and cytokine storm, which play a significant role in COVID-19 pathogenesis. Therefore, it seems that increasing zinc intake may be effective in the treatment of COVID-19 by reducing viral infection and preventing ARDS. So, it can be 
concluded that concomitant use of a standard drug with VitD, magnesium, and zinc may effectively control COVID 19 in the early stages and reduce mortality.

\begin{abstract}
Abbreviations
ACE2: Angiotensin-converting enzyme 2; ARDS: Acute respiratory distress syndrome; COVID-19: Coronavirus disease-19; DCs: Dendritic cells; IFN: Interferon; IL: Interleukin; JAK: Janus activated kinase; STAT: Signal transducer and activator of transcription; SARS-CoV-2: Severe acute respiratory syndrome coronavirus 2; TMPRSS2: Transmembrane protease/serine subfamily member 2; VitD:Vitamin D.
\end{abstract}

\section{Acknowledgements}

Not applicable.

\section{Authors' contributions}

All authors participated in writing. Writing-review, language correction \& editing were done by E. Bahreini and I. Alipourfard.

\section{Funding}

Not applicable.

\section{Availability of data and materials}

Data presented in this manuscript is available upon request.

\section{Declarations}

\section{Ethical Approval and Consent to participate}

Not applicable.

\section{Consent for publication}

All authors have read and approved the final version of the manuscript.

\section{Competing interests}

The authors declare that they have no competing interests.

\section{Author details}

'Department of Biochemistry, Faculty of Biological Science, Tarbiat Modares University, Tehran, Iran. ${ }^{2}$ Department of Molecular Cell Biology and Microbiology, Faculty of Biological Science and Technology, University of Isfahan, Isfahan, Iran. ${ }^{3}$ Nursing Department, Islamic Azad University, Khorasgan Branch, Isfahan, Iran. ${ }^{4}$ Institute of Biology, Biotechnology and Environmental Protection, Faculty of Natural Sciences, University of Silesia, Bankowa 9, 40-007 Katowice, Poland. ${ }^{5}$ Department of Biochemistry, Faculty of Medicine, Iran University of Medical Sciences, P.O. Box: 1449614525, Tehran, Iran.

Received: 6 September 2021 Accepted: 12 October 2021

Published online: 08 November 2021

\section{References}

1. Naqvi AAT, Fatima K, Mohammad T, Fatima U, Singh IK, Singh A, et al. Insights into SARS-CoV-2 genome, structure, evolution, pathogenesis and therapies: Structural genomics approach. Biochimica et biophysica acta Mol Basis Dis. 2020;1866(10):165878.

2. Atkinson B, Petersen E. SARS-CoV-2 shedding and infectivity. Lancet. 2020;395(10233):1339-40.

3. Guan WJ, Ni ZY, Hu Y, Liang WH, Ou CQ, He JX, et al. Clinical characteristics of Coronavirus disease 2019 in China. N Engl J Med. 2020;382(18):1708-20.

4. Gheblawi M, Wang K, Viveiros A, Nguyen Q, Zhong JC, Turner AJ, et al. Angiotensin-converting enzyme 2: SARS-CoV-2 receptor and regulator of the renin-angiotensin system: celebrating the 20th anniversary of the discovery of ACE2. Circ Res. 2020;126(10):1456-74.

5. Bestle D, Heindl MR, Limburg H, Pilgram O, Moulton H, et al. TMPRSS2 and furin are both essential for proteolytic activation of SARS-CoV-2 in human airway cells. Life Sci Alliance. 2020;3(9):e202000786.
6. Zolfaghari Emameh R, Falak R, Bahreini E. Application of system biology to explore the association of neprilysin, angiotensin-converting enzyme 2 (ACE2), and carbonic anhydrase (CA) in pathogenesis of SARS-CoV-2. Biol Proced Online. 2020;22:11.

7. Shulla A, Heald-Sargent T, Subramanya G, Zhao J, Perlman S, Gallagher T. A transmembrane serine protease is linked to the severe acute respiratory syndrome coronavirus receptor and activates virus entry. J Virol. 2011;85(2):873-82.

8. Bachler M, Bösch J, Stürzel DP, Hell T, Giebl A, Ströhle M, et al. Impaired fibrinolysis in critically ill COVID-19 patients. Br J Anaesth. 2021;126(3):590-8.

9. Fakhouri EW, Peterson SJ, Kothari J, Alex R, Shapiro JI, Abraham NG. Genetic polymorphisms complicate COVID-19 therapy: pivotal role of HO-1 in cytokine storm. Antioxidants (Basel, Switzerland). 2020;9(7):636.

10. Morris G, Bortolasci CC, Puri BK, Olive L, Marx W, O'Neil A, et al. The pathophysiology of SARS-CoV-2: a suggested model and therapeutic approach. Life Sci. 2020;258:118166.

11. Attia YA, Alagawany MM, Farag MR, Alkhatib FM, Khafaga AF, AbdelMoneim AE, et al. Phytogenic products and phytochemicals as a candidate strategy to improve tolerance to coronavirus. Front Vet Sci. 2020;7:573159.

12. Cinatl J, Morgenstern B, Bauer G, Chandra P, Rabenau H, Doerr HW. Treatment of SARS with human interferons. Lancet. 2003;362(9380):293-4.

13. Jayawardena R, Sooriyaarachchi P, Chourdakis M, Jeewandara C, Ranasinghe $P$. Enhancing immunity in viral infections, with special emphasis on COVID-19: a review. Diabetes Metab Syndr. 2020;14(4):367-82.

14. Alagawany M, Attia YA, Farag MR, Elnesr SS, Nagadi SA, Shafi ME, et al. The strategy of boosting the immune system under the COVID-19 pandemic. Front Vet Sci. 2020;7:570748

15. Esakandari H, Nabi-Afjadi M, Fakkari-Afjadi J, Farahmandian N, Miresmaeili SM, Bahreini E. A comprehensive review of COVID-19 characteristics. Biol Proced Online. 2020;22:19.

16. Zhao Z, Wei Y, Tao C. An enlightening role for cytokine storm in coronavirus infection. Clin Immunol (Orlando, Fla). 2021;222:108615.

17. Costela-Ruiz VJ, Illescas-Montes R, Puerta-Puerta JM, Ruiz C, MelguizoRodríguez L. SARS-CoV-2 infection: the role of cytokines in COVID-19 disease. Cytokine Growth Factor Rev. 2020;54:62-75.

18. Wong CK, Ho CY, Ko FW, Chan CH, Ho AS, Hui DS, et al. Proinflammatory cytokines (IL-17, IL-6, IL-18 and IL-12) and Th cytokines (IFN-gamma, IL-4, IL-10 and IL-13) in patients with allergic asthma. Clin Exp Immunol. 2001;125(2):177-83.

19. Chen Z, John WE.T cell responses in patients with COVID-19. Nat Rev Immunol. 2020;20(9):529-36.

20. Li G, Fan Y, Lai Y, Han T, Li Z, Zhou P, et al. Coronavirus infections and immune responses. J Med Virol. 2020;92(4):424-32.

21. Min JY, Jang YJ. Macrolide therapy in respiratory viral infections. Mediators Inflamm. 2012;2012:649570.

22. Bagheri A, Moezzi SMI, Mosaddeghi P, NadimiParashkouhi S, FazelHoseini SM, Badakhshan F, et al. Interferon-inducer antivirals: potential candidates to combat COVID-19. Int Immunopharmacol. 2021;91:107245.

23. Hajimirzaei N, Khalili NP, Boroumand B, Safari F, Pourhosseini A, Judi-Chelan R, et al. Comparative study of the effect of macrolide antibiotics erythromycin, clarithromycin, and azithromycin on the ERG1 gene expression in H9c2 cardiomyoblast cells. Drug Res (Stuttg). 2020;70(8):341-7.

24. Rutigliano JA, Sharma S, Morris MY, Oguin TH 3rd, McClaren JL, Doherty $P C$, et al. Highly pathological influenza A virus infection is associated with augmented expression of PD-1 by functionally compromised virusspecific CD8+ T cells. JVirol. 2014;88(3):1636-51.

25. Pauken KE, Godec J, Odorizzi PM, Brown KE, Yates KB, Ngiow SF, et al. The PD-1 pathway regulates development and function of memory CD8(+) T cells following respiratory viral infection. Cell Rep. 2020;31(13):107827.

26. Cullen JG, McQuilten HA, Quinn KM, Olshansky M, Russ BE, Morey A, et al. CD4(+)T help promotes influenza virus-specific CD8(+) T cell memory by limiting metabolic dysfunction. Proc Natl Acad Sci U S A. 2019;116(10):4481-8.

27. Tarke A, Sidney J, Methot N, Zhang Y, Dan JM, Goodwin B, et al. Negligible impact of SARS-CoV-2 variants on CD4 (+) and CD8 $(+)$ T cell reactivity in COVID-19 exposed donors and vaccinees. bioRxiv. 2021;384:403. 
28. Diao B, Wang C, Tan Y, Chen X, Liu Y, Ning L, et al. Reduction and functional exhaustion of T cells in patients with coronavirus disease 2019 (COVID-19). Front Immunol. 2020;11:827.

29. Xia H, Cao Z, Xie X, Zhang X, Chen JYC, Wang H, et al. Evasion of type I interferon by SARS-CoV-2. Cell Rep. 2020;33(1):108234.

30. Horvath CM. The Jak-STAT pathway stimulated by interferon alpha or interferon beta. Sci STKE. 2004;2004(260):tr10.

31. Tsuno T, Mejido J, Zhao T, Schmeisser H, Morrow A, Zoon KC. IRF9 is a key factor for eliciting the antiproliferative activity of IFN-alpha. J Immunother. 2009;32(8):803-16

32. Martinez NE, Sato F, Kawai E, Omura S, Chervenak RP, Tsunoda I. Regulatory T cells and Th17 cells in viral infections: implications for multiple sclerosis and myocarditis. Futur Virol. 2012;7(6):593-608.

33. Wu W, Dietze KK, Gibbert K, Lang KS, Trilling M, Yan H, et al. TLR ligand induced IL-6 counter-regulates the anti-viral CD8 $+T$ cell response during an acute retrovirus infection. Sci Rep. 2015;5(1):1-14.

34. Velazquez-Salinas L, Verdugo-Rodriguez A, Rodriguez LL, Borca MV. The role of interleukin 6 during viral infections. Front Microbiol. 2019;10:1057.

35. Haji Abdolvahab M, Moradi-Kalbolandi S, Zarei M, Bose D, MajidzadehA K, Farahmand L. Potential role of interferons in treating COVID-19 patients. Int Immunopharmacol. 2021;90:107171.

36. Shinozawa $Y$, Matsumoto T, Uchida $K$, Tsujimoto S, I wakura Y, Yamaguchi K. Role of interferon-gamma in inflammatory responses in murine respiratory infection with Legionella pneumophila. J Med Microbiol. 2002;51(3):225-30.

37. Tateda K, Ishii Y, Matsumoto T, Kobayashi T, Miyazaki S, Yamaguchi K. Potential of macrolide antibiotics to inhibit protein synthesis of Pseudomonas aeruginosa: suppression of virulence factors and stress response. J Infect Chemother. 2000;6(1):1-7.

38. Sugamata R, Sugawara A, Nagao T, Suzuki K, Hirose T, Yamamoto K, et al. Leucomycin A3, a 16-membered macrolide antibiotic, inhibits influenza A virus infection and disease progression. J Antibiot (Tokyo). 2014;67(3):213-22.

39. Bleyzac N, Goutelle S, Bourguignon L, Tod M. Azithromycin for COVID-19: more than just an antimicrobial? Clin Drug Investig. 2020;40(8):683-6.

40. Du X, Zuo X, Meng F, Han C, Ouyang W, Han Y, et al. Direct inhibitory effect on viral entry of influenza A and SARS-CoV-2 viruses by azithromycin. Cell Prolif. 2021;54(1):e12953.

41. Menzel M, Akbarshahi H, Bjermer L, Uller L. Azithromycin induces antiviral effects in cultured bronchial epithelial cells from COPD patients. Sci Rep. 2016;6:28698.

42. Bagheri A, Moezzi SMI, Mosaddeghi P, Nadimi Parashkouhi S, Fazel Hoseini SM, Badakhshan F, et al. Interferon-inducer antivirals: Potential candidates to combat COVID-19. Int Immunopharmacol. 2021:91:107245.

43. Li C, Zu S, Deng YQ, Li D, Parvatiyar K, Quanquin N, et al. Azithromycin protects against Zika virus infection by upregulating virus-induced type I and III interferon responses. Antimicrob Agents Chemother. 2019;63(12):e00394-19.

44. Schofield KP, Potter C, Phair J, Oxford J, Jennings R. Effect of ribavirin on influenza virus infection in ferrets. Parasites, fungi, and viruses. Springer; 1976. p. 253-70.

45. Meier V, Bürger E, Mihm S, Saile B, Ramadori G. Ribavirin inhibits DNA, RNA, and protein synthesis in PHA-stimulated human peripheral blood mononuclear cells: possible explanation for therapeutic efficacy in patients with chronic HCV infection. J Med Virol. 2003;69(1):50-8.

46. Khakoo S, Glue P, Grellier L, Wells B, Bell A, Dash C, et al. Ribavirin and interferon alfa- $2 b$ in chronic hepatitis $C$ : assessment of possible pharmacokinetic and pharmacodynamic interactions. $\mathrm{Br} J \mathrm{Clin}$ Pharmacol. 1998;46(6):563-70.

47. Unal MA, Bitirim CV, Summak GY, Bereketoglu S, Zeytin IC, Bul O, et al. Ribavirin shows antiviral activity against SARS-CoV- 2 and downregulates the activity of TMPRSS2 and the expression of ACE2 In Vitro. bioRxiv. 2020;41(6):363.

48. Elfiky AA. Ribavirin, Remdesivir, Sofosbuvir, Galidesivir, and Tenofovir against SARS-CoV-2 RNA dependent RNA polymerase (RdRp): a molecular docking study. Life Sci. 2020;253:117592.

49. Reddy P, Edwards LR. Magnesium supplementation in vitamin D deficiency. Am J Ther. 2019;26(1):e124-32.

50. Read SA, Obeid S, Ahlenstiel C, Ahlenstiel G. The role of zinc in antiviral immunity. Adv Nutr (Bethesda, Md). 2019;10(4):696-710.
51. Aranow C. Vitamin $D$ and the immune system. J Investig Med. 2011;59(6):881-6.

52. Martineau AR, Jolliffe DA, Greenberg L, Aloia JF, Bergman P, Dubnov-Raz $\mathrm{G}$, et al. Vitamin D supplementation to prevent acute respiratory infections: individual participant data meta-analysis. Health Technol Assess. 2019;23(2):1-44.

53. Ajabshir $S$, Asif $A$, Nayer $A$. The effects of vitamin $D$ on the renin-angiotensin system. J Nephropathol. 2014;3(2):41-3.

54. Selvaraj P, Harishankar M, Singh B, Banurekha W, Jawahar MS. Effect of vitamin D3 on chemokine expression in pulmonary tuberculosis. Cytokine. 2012;60(1):212-9.

55. Malek Mahadavi A. A brief review of interplay between vitamin D and angiotensin-converting enzyme 2: implications for a potential treatment for COVID-19. Revi Med Virol. 2020;30(5):e2119-e.

56. Li YC, Qiao G, Uskokovic M, Xiang W, Zheng W, Kong J. Vitamin D: a negative endocrine regulator of the renin-angiotensin system and blood pressure. J Steroid Biochem Mol Biol. 2004;89-90(1-5):387-92.

57. Ishii K, Takeuchi H, Fukunaga K, Hirano Y, Suda K, Hagiwara T, et al. Attenuation of lipopolysaccharide-induced acute lung injury after (pro)renin receptor blockade. Exp Lung Res. 2015;41(4):199-207.

58. Takano Y, Mitsuhashi $H$, Ueno K. 1a,25-Dihydroxyvitamin $D_{3}$ inhibits neutrophil recruitment in hamster model of acute lung injury. Steroids. 2011;76(12):1305-9.

59. Nurminen V, Seuter S, Carlberg C. Primary vitamin D target genes of human monocytes. Front Physiol. 2019;10:194.

60. Chung C, Silwal P, Kim I, Modlin RL, Jo E-K. Vitamin D-cathelicidin axis: at the crossroads between protective immunity and pathological inflammation during infection. Immune Netw. 2020;20(2):e12-e.

61. Kuroda K, Okumura K, Isogai H, Isogai E. The human cathelicidin antimicrobial peptide LL-37 and mimics are potential anticancer drugs. Front Oncol. 2015:5:144.

62. Weber G, Heilborn JD, Chamorro Jimenez Cl, Hammarsjo A, Törmä H, Stahle M. Vitamin D induces the antimicrobial protein hCAP18 in human skin. J Invest Dermatol. 2005;124(5):1080-2.

63. Tada H, Shimizu T, Nagaoka I, Takada H. Vitamin D3 analog maxacalcitol (OCT) induces hCAP-18/LL-37 production in human oral epithelial cells. Biomed Res. 2016;37(3):199-205.

64. Currie SM, Gwyer Findlay E, McFarlane AJ, Fitch PM, Böttcher B, Colegrave $\mathrm{N}$, et al. Cathelicidins have direct antiviral activity against respiratory syncytial virus in vitro and protective function in vivo in mice and humans. J Immunol. 2016;196(6):2699-710.

65. Crane-Godreau MA, Clem KJ, Payne P, Fiering S. Vitamin D deficiency and air pollution exacerbate COVID-19 through suppression of antiviral peptide LL37. Front Public Health. 2020;8:232.

66. Leaf-nosed bat. Encyclopædia Britannica: Encyclopædia Britannica Online: 2009.

67. Saul L, Mair I, Ivens A, Brown P, Samuel K, Campbell JDM, et al. 1,25-Dihydroxyvitamin $D(3)$ restrains $C D 4(+) T$ cell priming ability of $C D 11 C(+)$ dendritic cells by upregulating expression of CD31. Front Immunol. 2019;10:600.

68. Li YC, Chen Y, Liu W, Thadhani R. MicroRNA-mediated mechanism of vitamin D regulation of innate immune response. J Steroid Biochem Mol Biol. 2014;144(Pt A):81-6.

69. Buitrago CG, Ronda AC, de Boland AR, Boland R. MAP kinases p38 and JNK are activated by the steroid hormone 1alpha,25(OH)2-vitamin D3 in the C2C12 muscle cell line. J Cell Biochem. 2006;97(4):698-708.

70. Pardo VG, Boland R, de Boland AR. 1alpha,25(OH)(2)-Vitamin D(3) stimulates intestinal cell p38 MAPK activity and increases c-Fos expression. Int J Biochem Cell Biol. 2006;38(7):1181-90.

71. Esfandiar N, Alaei F, Fallah S, Babaie D, Sedghi N. Vitamin D deficiency and its impact on asthma severity in asthmatic children. Ital J Pediatr. 2016:42(1):1-6.

72. Jat KR, Khairwa A. Vitamin D and asthma in children: a systematic review and meta-analysis of observational studies. Lung India. 2017;34(4):355-63.

73. Im JH, Je YS, Baek J, Chung MH, Kwon HY, Lee JS. Nutritional status of patients with COVID-19. Int J Infect Dis. 2020;100:390-3.

74. Nielsen FH. Magnesium deficiency and increased inflammation: current perspectives. J Inflamm Res. 2018;11:25. 
75. Dai Q, Zhu X, Manson JE, Song Y, Li X, Franke AA, et al. Magnesium status and supplementation influence vitamin D status and metabolism: results from a randomized trial. Am J Clin Nutr. 2018;108(6):1249-58.

76. Young KA, Munroe ME, Guthridge JM, Kamen DL, Niewold TB, Gilkeson GS, et al. Combined role of vitamin D status and CYP24A1 in the transition to systemic lupus erythematosus. Ann Rheum Dis. 2017;76(1):153-8.

77. McMullan CJ, Borgi L, Curhan GC, Fisher N, Forman JP. The effect of vitamin $\mathrm{D}$ on renin-angiotensin system activation and blood pressure: a randomized control trial. J Hypertens. 2017;35(4):822-9.

78. Rerksuppaphol S, Rerksuppaphol L. A randomized controlled trial of zinc supplementation as adjuvant therapy for dengue viral infection in Thai children. Int J Prev Med. 2018;9:88.

79. Singh M, Das RR. Zinc for the common cold. Cochrane Database Syst Rev. 2013;6:cd001364.

80. Fani M, Khodadad N, Ebrahimi S, Nahidsamiei R, Makvandi M, Teimoori A, et al. Zinc sulfate in narrow range as an in vitro anti-HSV-1 assay. Biol Trace Elem Res. 2020;193(2):410-3.

81. Read SA, Obeid S, Ahlenstiel C, Ahlenstiel G. The role of zinc in antiviral immunity. Adv Nutr. 2019;10(4):696-710.

82. Haase $H$, Rink $L$. The immune system and the impact of zinc during aging. Immun Ageing. 2009;6(1):9.

83. Dardenne M, Prasad A, Bach J-F, editors. Zinc and Thymulin. Tokyo: Springer Japan; 1990

84. Maywald M, Wang F, Rink L. Zinc supplementation plays a crucial role in Thelper 9 differentiation in allogeneic immune reactions and non-activated T cells. J Trace Elem Med Biol. 2018;50:482-8.
85. Gao H, Dai W, Zhao L, Min J, Wang F. The role of zinc and zinc homeostasis in macrophage function. J Immunol Res. 2018;2018:6872621.

86. Rink L, Kirchner H. Zinc-altered immune function and cytokine production. J Nutr. 2000;130(5S Suppl):1407s-s1411.

87. Fu M, Blackshear PJ. RNA-binding proteins in immune regulation: a focus on CCCH zinc finger proteins. Nat Rev Immunol. 2017;17(2):130-43.

88. Dáňová K, Klapetková A, Kayserová J, Šedivá A, Špíšek R, Jelínková LP. NF-KB, p38 MAPK, ERK1/2, mTOR, STAT3 and increased glycolysis regulate stability of paricalcitol/dexamethasone-generated tolerogenic dendritic cells in the inflammatory environment. Oncotarget. 2015;6(16):14123-38.

89. Nuttall JR, Oteiza PI. Zinc and the ERK kinases in the developing brain. Neurotox Res. 2012;21(1):128-41.

90. Guo D, Zhou H, Wu Y, Zhou F, Xu G, Wen H, et al. Involvement of ERK1/2/NF-KB signal transduction pathway in TF/FVIla/PAR2-induced proliferation and migration of colon cancer cell SW620. Tumour Biol. 2011;32(5):921-30

91. Bao B, Prasad AS, Beck FW, Godmere M. Zinc modulates mRNA levels of cytokines. Am J Physiol Endocrinol Metab. 2003;285(5):E1095-102.

92. Aydemir TB, Liuzzi JP, McClellan S, Cousins RJ. Zinc transporter ZIP8 (SLC39A8) and zinc influence IFN-gamma expression in activated human T cells. J Leukoc Biol. 2009;86(2):337-48.

\section{Publisher's Note}

Springer Nature remains neutral with regard to jurisdictional claims in published maps and institutional affiliations.
Ready to submit your research? Choose BMC and benefit from:

- fast, convenient online submission

- thorough peer review by experienced researchers in your field

- rapid publication on acceptance

- support for research data, including large and complex data types

- gold Open Access which fosters wider collaboration and increased citations

- maximum visibility for your research: over $100 \mathrm{M}$ website views per year

At BMC, research is always in progress.

Learn more biomedcentral.com/submissions 